\title{
Epidemiologia das Infecções Diarréicas entre Populações Indígenas da Amazônia
}

\section{Epidemiology of Diarrhea Infection among Indian Populations of Amazonia}

\author{
Alexandre C. Linhares ${ }^{1}$ \\ LINHARES, A. C. Epidemiology of Diarthea Infection among Indian Populations of \\ Amazonia. Cad. Saude Públ., Rio de Janeiro, 8 (2): 121-128, abr/jun, 1992.
}

Bacteria, viruses and parasites have frequently been associated with gastroenteritis among Amerindians living in the Amazon region. Shigella flexneri has been found in $4 \%$ of diarrhoeic specimens collected from Parakanã Indians. In addition, antibodies to the $\mathrm{E}$. coli labile toxin have been detected in $98 \%$ of Indians belonging to the Menkrangnoti, Parakanã, Xikrín and Asurini communities. Both wild edentata and marsupials seem to be important Salmonella sp. reservoirs as studies have demonstrated the occurrence of infection in $63 \%$ and $20 \%$ of them, respectively. Shigella disenteriae has been isolated from $4.2 \%$ of Suruí Amerinds. Among the Karitiána, Shigella boydii (one isolate) and $\mathrm{E}$. coli (11 isolates) were recovered from 85 specimens processed for bacterial enteropathogens. Rotaviruses were the causative agent of an extensive outbreak of diarrhoea among the Tiriyo, in July-August, 1977. By using the counterimmune-electro-osmophoresis, seroconversions were detected in $25.6 \%$ of paired (pre-and post-epidemic) serum samples. Birmingham serotype I was identified as the causative agent of the outbreak, which affected at least $80 \%$ of the population at risk: the clinical attack rates were more prominent among both young children and the elderly. Studies on the prevalence of rotavirus antibody among 13 Indian communities in the Amazon region yielded, in general, positivity rates greater than 50\%. However, the Parakanã Novo were found to be non-immune to rotaviruses. The increasing rates of seropositivity with age suggest the persistence of rotaviruses in these communities; in addition, high rates of positivity among young children suggest that rotavirus infection may be endemic. Both Suruí and Karitiána were found to have high prevalence rates of rotavirus antibody: 67.8 and 77.4, respectively. Wild marsupials may possibly play a role in the transmission of rotaviruses among Indians. Parasites have also been associated with gastrointestinal disease among Indians in the Amazon region. S. stercoralis and Entamoeba hystolitica have been detected among the Suruí in frequencies of 33.3\%, 3.3\% and $0.8 \%$, respectively. Among the Pacaánova the same parasites have been recorded in frequencies of $3.9 \%, 12.7 \%$ and $8.8 \%$, respectively. Entamoeba hystolitica was found in $40 \%$ of the Yanomámi. The poor sanitation conditions and hygiene practices, as well as the possibility of the contact of Indians with wild reservoirs, account for the spread of enteropathogens within these communities in the Amazon region. Special precautions should be currently taken with respect to the possibility of the introduction of cholera among these Amerindians.

Keywords: Amerindians; Diarrhea; Amazon Region

Pelo menos uma centena de diferentes tribos indígenas se distribuem na região amazônica,

\footnotetext{
${ }^{1}$ Instituto Evandro Chagas, Fundação Nacional de Saude. Av. Almirante Barraso, 492, Belém, PA, 66090 $\infty$, BrasiL
}

exibindo graus de aculturação diversos - em função dos primeiros contatos regulares estabelecidos com o homem urbano - e reunindo contingentes populacionais que variam desde algumas dezenas até milhares de integrantes. Embora já se denote uma expressiva interferên- 
cia no contexto cultural dessas naçôes, exacerbada nas duas últimas décadas face à contínua implementação dos projetos de desenvolvimento, ainda são preservadas, em algumas delas, características que se configuram como primárias. Emergem, portanto, atualmente, duas condições epidemiológicas distintas: uma, representada pelos núcleos populacionais em que o contato com o homem urbano já se caracteriza como sistemático, e outra, que reflete um intercâmbio ocasional, prevalecendo um relativo grau de isolamento. De modo geral, as condiçōes de saneamento são precárias, inexistindo infra-estrutura que viabilize a destinação adequada dos dejetos, bem como o acesso a água de boa qualidade. Constitui-se em prática rotineira a utilização dos cursos de água (rios, igarapés, etc.) para o asseio corporal, lavagem dos utensílios e, eventualmente, emissão dos dejetos humanos e animais. Tal panorama sanitário enseja o estabelecimento de condições propícias à propagação de patógenos entéricos, particularmente os introduzidos a partir da área urbana.

Embora limitadas a algumas comunidades indígenas da região amazônica, as investigações científicas acerca das diarréias agudas (e agentes etiológicos correlatos) até então empreendidas denotam situações que variam desde as endemias até extensos episódios de natureza epidêmica. Nesse contexto, alguns resultados, a seguir resumidos, retratam a magnitude que assumem os quadros diarréicos entre esses amerindios, do qual se pode inferir - num contexto global - o expressivo impacto em termos de morbi-mortalidade daí resultante.

\section{Algumas Obsenvaçöes Pioneiras sobre Entero-Patógenos Bacterianos}

Estudos levados a efeito por Pinheiro et al. (1974), à época em que se iniciavam as tentativas de colonização da Estrada Transamazônica, revelaram a ocorrência de enterobactérias dotadas de patogenicidade para o homem entre migrantes que se estabeleciam ao longo da Transamazônica. Procederam-se a 418 coprocultivos envolvendo espécimes obtidos dos colonos, assim como se examinaram - com o intuito de detectar-se Salmonella $s p$. - amostras de intestinos delgado e grosso oriundas de
1.432 animais silvestres capturados em áreas adjacentes aos aglomerados populacionais. Daf decorreram isolamentos de Salmonella $s p$. (sorogrupos B e C2) e Shigella disenteriae em número de três e duas cepas, respectivamente, a partir dos espécimes de origem humana. Por outro lado, lograram-se quatro deteç̧ões de Salmonella sp. (duas amostras pertencentes ao sorogrupo $B$, uma ao $C 2$ e outra ao subgênero IV), como resultados dos exames a que foram submetidos os materiais de origem animal. Embora não dirigidas especificamente a grupos indígenas, tais investigações abrangeram pessoas e animais em íntimo contato com a floresta, representando, por conseguinte, fontes $\mathrm{em}$ potencial de infecção para aquelas populações nativas próximas. A situação em foco permite inferir que o risco de enteroinfecções bacterianas entre os silvícolas não emana, estritamente, de eventuais contatos que se possam estabelecer com o homem urbano. $O$ isolamento de salmonelas (agentes de reconhecida importância médica) a partir de espécimes oriundos de animais silvestres, nitidamente configura o potencial infectante existente no hábitat natural dos índios. Evidentemente que a conjunção dos dois fatores exacerba os riscos no tocante às infecções por enteropatógenos nessas comunidades.

Consubstanciando as informações anteriores, são dignos de nota os achados de Lins (1983), quanto à prevalência de enterobactérias patogênicas em populações indígenas da Amazônia. Investigações procedidas em 26 indivíduos da tribo Parakanãs, Pará (a $360 \mathrm{~km}$ da rodovia Marabá-Tucuruí), revelaram frequiência da ordem de 4\% para Shigella flexneri, reconhecidamente associada a quadros disentéricos de natureza severa. Outro resultado que se revestiu de particular relevância foi a deteç̧ão de anticorpos (classe $\mathrm{IgG}$ ) para a toxina lábil de $E$. coli em $98,4 \%$ de 307 amostras de soro obtidas de índios pertencentes às tribos Menkrangnoti, Parakanã, Xikrin e Asurini. Apesar do relativo isolamento dessas comunidades, são notórios os indicadores de infecçōes pregressas por cepas enteropatogênicas de $E$. coli, também caracterizadas como bactérias de expressão em termos de patogenicidade para o homem. Ainda com base em observações de Lins (1983), consolidam-se as evidências no tocante ao papel que 
animais silvestres podem desempenhar no mecanismo de transmissão das enterobactérias aos indígenas. Ressaltem-se, nesse contexto, isolamentos de Salmonella sp. em 27 (2\%) dentre 1380 espécimes capturados durante a construção da rodovia Belém-Brasilia. À época em que eram levados a efeito esses estudos, também foram examinados quelônios (muçuãs, Kinostermon scorpioides) da ilha de Marajó, que revelaram surpreendentes indices de infecção por Salmonella sp., cerca de $50 \%$. Pesquisas mais recentes, conduzidas no periodo de 1980 a 1986, envolveram 519 animais silvestres, pertencentes às ordens Rodentia, Edentata, Marsupialia, Chiroptera, Carnivora e Primata, capturados em área de selva nas regiōes de Monte Dourado, Serra dos Carajás e ilha de Marajó, no Pará. As salmonelas foram detectadas em $8,7 \%$ do total de espécimes examinados. Destaquem-se, entre os animais estudados, como reservatórios mais expressivos os edentados (63\% de positividade) e os marsupiais (20\%). Apesar dos animais se constituírem em reconhecida fonte de infecção para o homem, por $Y$. enterocolitica e Campylobacter jejuni, tais enteropatógenos não foram detectados em 198 espécimens silvestres também estudados na região amazônica por Lins (1983).

Coimbra Jr. et al. (1985) procederam a exames bacteriológicos em amostras fecais de índios Surui e Karitiána, em Rondônia, detectando enteropatógenos de importância. Assim é que, no primeiro grupo, isolaram-se amostras de Shigella disenteriae em $2(4,2 \%)$ de 40 indivíduos examinados, enquanto no segundo, das 85 coproculturas processadas, resultaram o isolamento de Shigella boydii em um caso e de $E$. coli patogênicas em outras 11 situações envolvendo oito sorotipos clássicos, duas cepas invasivas e uma enterotoxigênica.

\section{Gastroenterites Agudas Associadas a Rotavirus}

\section{Surto Epidêmico em Tiriyó, Pará}

Em julho/agosto de 1977, um surto explosivo de diartéia envolvendo os indios Tiriyó, que habitam o norte do Pará, fronteira com o Suriname, foi notificado ao Instituto Evandro Chagas (IEC) por médicos atuantes na Força Aérea
Brasileira (FAB). A ocorrência se caracterizava como de propagação extremamente rápida, acometendo, em particular, crianças de baixa idade (Linhares et al., 1981). Tais condiçōes suscitaram, de imediato, a hipótese de etiologia virótica, motivando repetidas incursões de natureza científica àquela aldeia.

A população, à época do surto epidêmico, era constituida de 224 indivíduos, 154 pertencentes à tribo Tiriyó, 62, à Kaxuyána e 8, à Ewarrhoyana. Os estudos visando à elucidação da etiologia se fundamentaram na pesquisa de anticorpos para rotavírus em amostras de soro coletadas antes (disponíveis no banco do IEC) e depois da epidemia. Com base no exame de 168 espécimes pareados pelo método da contra-imuno-eletro-osmoforese, detectaram-se soroconversões para rotavírus em $127(25,6 \%)$ situaçōes, o que nitidamente incriminou esse agente como o determinante etiológico. Testes de neutralização baseados na imunofluorescência indireta, envolvendo 16 pares de soro, revelaram que o sorotipo I (Birmingham) se constituiu no agente causal, considerando a ampla predominância de soroconversões registrada para essa variedade antigênica.

Do ponto de vista epidemiológico, o surto em Tiriyó caracterizou-se como singular sob vários aspectos. Diferentemente do que se observa no âmbito urbano, a epidemia abrangeu adultos e crianças, prevalecendo mais expressiva frequiència, entretanto, nessas últimas (Figura 1). Digno de nota, ainda, foi o registro do elevado índice de positividade $(80 \%)$ no grupo reunindo os indivíduos com 41 anos ou mais de idade.

Clinicamente, os quadros de gastroenterite observados se revestiram de maior severidade entre as crianças menores de cinco anos. $O$ elenco de manifestações clínicas envolvia, quase que sistematicamente, diarréia aquosa, cólicas abdominais, hipertermia e desidratação. Apenas uma ocorrência fatal foi assinalada, envolvendo uma criança com um ano de idade; porém, não fosse a pronta intervenção dos médicos da FAB, o impacto em termos de mortalidade seria certamente expressivo.

Com o intuito de estabelecer-se a origem da infecção, investigações retrospectivas foram levadas a efeito, sustentando-se a hipótese de que o vírus foi introduzido na comunidade a partir de um silvícola que retornou de Belém 
FIGURA 1 - Soroconversões para Rotavírus em 158 Indios Tiriyó agrupados de acordo com a idade

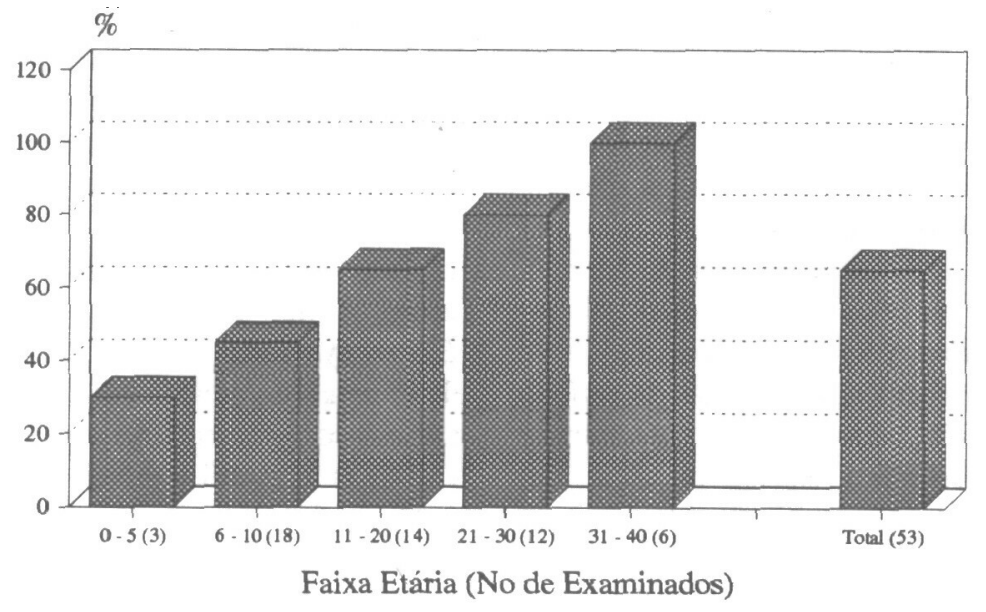

(onde realizou tratamento de doença respiratória) à aldeia com diarréia. Com efeito, os familiares desse indio, bem como os vizinhos mais próximos, foram os primeiros a adoecer; a partir desses eventos iniciais, desencadeou-se a epidemia, em caráter explosivo. Admitimos que as precárias condiçōes de higiene reinantes na área tenham contribuído decisivamente para a disseminação do vírus entre suscetíveis. Nesse contexto, destaque-se o papel da água na veiculação dos rotavírus.

\section{Estudo da Prevalência de Anticorpos para Rotavirus}

Estudos de soroprevaléncia foram empreendidos em 13 comunidades indígenas da região amazônica, com o objetivo básico de avaliar-se o grau de dispersão dos rotavírus em populaçōes ainda sujeitas a relativo grau de isolamento (Linhares et al., 1986b). Utilizando-se o procedimento imuno-enzimático e a imunofluorescência indireta, observou-se que, em geral, elevados índices de positividade são registrados, sugerindo contato freqüente com os vínus em questão (Tabela 1). Os Parakanã Novo, entretanto, revelaram-se amplamente não imunes aos rotavínus, reunindo, portanto, condiçōes favoráveis à eclosão de uma epidemia similar à descrita anteriormente, em relação aos Tiriyó. Em algumas situações, como a relativa aos Mayongóngs (Figura 2), a prevalência de anticorpos aumenta regularmente com a idade, sugerindo a persistência dos rotavírus nesses aglomerados humanos. Por outro lado, a quase sistemática obtenção de resultados positivos em crianças de baixa idade configura o caráter endêmico de que se revestem as infecções por rotavírus nesses núcleos humanos. Tais peculiaridades epidemiológicas, ressalte-se, divergem do que preceitua Albert et al. (1983); com efeito, tais autores estimam em 5.000 indivíduos o número crítico, e mínimo, para que os agentes virais em questão se estabeleçam endemicamente. Nenhuma das populações investigadas, no entanto, reunía tal contingente de integrantes.

Uma questão básica que suscita à análise dos expressivos percentuais de soroprevalência acima especificados reside no mecanismo de manutenção dos rotavirus em tais comunidades. Introduções esporádicas desses enteropatógenos nas populações sob estudo, a partir do homem urbano, se constituiriam, certamente, num fator determinante desses elevados indices de positividade quanto à presença de anticorpos específicos. Por outro lado, o papel que animais silvestres desempenhariam, como reservatórios dos rotavírus, deve ser considerado. Nesse particular, são pertinentes os achados de Linhares et. al (1986a), que detectaram amostras de rotavírus em espécimes fecais obtidos de $2(1,35 \%)$ entre 148 marsupiais capturados na Serra dos Carajás, Pará, área de floresta. O contato eventual dos silvícolas com esses reservatórios 
TABELA 1 - Prevalência de Anticorpos para Rotavírus em Treze Tribos Indígenas da Região Amazônica

\begin{tabular}{lcrrrr}
\hline \hline Tribos & $\begin{array}{c}\text { Média das } \\
\text { Idades } \\
\text { (anos) }\end{array}$ & \multicolumn{2}{c}{ Elisa } & \multicolumn{2}{c}{ IF } \\
\cline { 3 - 6 } & 22,4 & $96 / 144$ & $(66,7)$ & $35 / 144$ & $(24,3)$ \\
Apalaí & 34,5 & $27 / 53$ & $(50,9)$ & $3 / 53$ & $(5,7)$ \\
Asuriní & 34,1 & $42 / 45$ & $(93,3)$ & $13 / 45$ & $(28,9)$ \\
Kubenkrankégn & 27,3 & $34 / 53$ & $(64,1)$ & $37 / 54$ & $(68,5)$ \\
Mayongóng & 21,7 & $46 / 91$ & $(50,5)$ & $28 / 91$ & $(30,8)$ \\
Menkrangnotí & 16,8 & $70 / 96$ & $(72,9)$ & $67 / 98$ & $(68,3)$ \\
Oyampi & 18,9 & $5 / 28$ & $(17,9)$ & $3 / 28$ & $(10,7)$ \\
Parakanã Novo & 28,4 & $52 / 61$ & $(85,2)$ & $17 / 61$ & $(27,9)$ \\
Parakanã Velho & 25,5 & $35 / 61$ & $(57,4)$ & $45 / 61$ & $(73,8)$ \\
Sanumá & 21,7 & $92 / 157$ & $(58,6)$ & $64 / 157$ & $(40,8)$ \\
Tiriyó & 22,5 & $156 / 387$ & $(40,3)$ & $118 / 347$ & $(34,0)$ \\
Tukáno & 24,0 & $38 / 77$ & $(49,3)$ & $2 / 76$ & $(2,6)$ \\
Xikrín & $?$ & $18 / 46$ & $(39,1)$ & $18 / 46$ & $(39,1)$ \\
Yanomámi & - & $711 / 1299$ & $(54,7)$ & $450 / 1261$ & $(35,6)$ \\
\hline Total & & & & & \\
\hline \hline
\end{tabular}

* Alguns soros esgotaram em testes preliminares

? Idades não disponiveis

FIGURA 2 - Taxa de Imunidade para Rotavirus, por Faixa Etária, entre os Mayongóngs

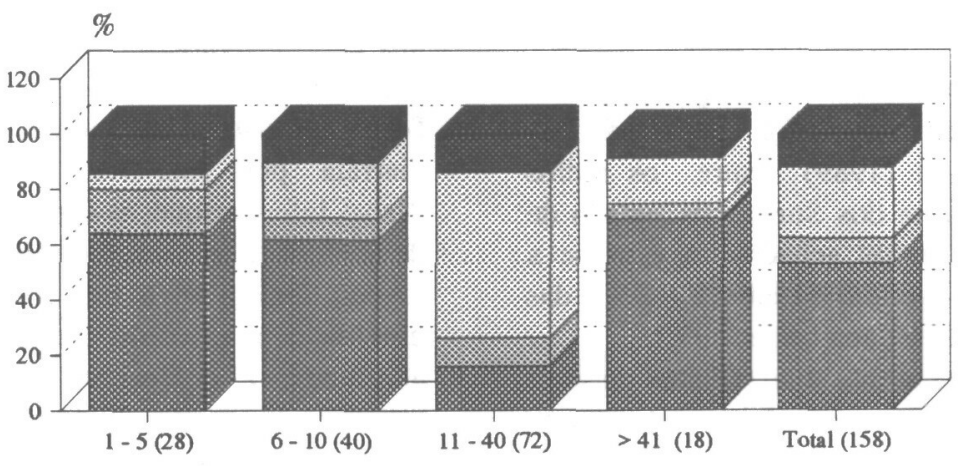

Faixa Etária (No de individuos)

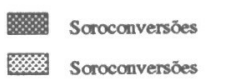

animais, como fonte de persistência dos rotavírus nessas comunidades, merece estudos ulteriores, mais amplos.

Investigações recentes conduzidas por Santos et al. (1991) também revelaram expressivas taxas de positividade quanto à presença de
Sem Soroconversōes

Sem Soroconversōes

anticorpos para rotavírus nos grupos indígenas Surui $(67,8 \%)$ e Karitiána $(77,4 \%)$, situados em Rondônia. Todos as grupos etários, nessas populaçōes, exibiam elevadas taxas de soropositivos, o que denota contínua exposição a esses virus. 


\section{Enteroparasitas e Quadros Diarréicos}

Dados sobre a ocorrência de enteroparasitoses entre indígenas são escassos, embora configurem a sua relevảncia na gênese dos quadros de gastroenterite aguda ou crônica. De modo geral, tanto a transmissão direta como a indireta decorrem da contaminação fecal do meio ambiente, condição que prevalece amplamente nas aldeias.

Entre outros enteroparasitas detectados, Coimbra Jr. \& Mello (1981) registraram, entre os indios da comunidade tribal Surui, Rondônia, Strongyloides stercoralis, Giardia lamblia e Entamoeba hystolitica complex em freqüências de $33,3 \%, 3,3 \%$ e $0,8 \%$, respectivamente, a partir do exame procedido em 200 espécimes fecais. Os autores sustentam que a poluição do peridomicílio, nessa comunidade, por restos alimentares e material fecal decorre do sedenta rismo que se impõe a essa comunidade, daí resultando condições propícias à contaminação do solo por formas infectantes dos enteroparasitas. Também são dignos de nota os achados de Santos et al. (1985), que descreveram a ocorrência de $S$. stercoralis, $G$. lamblia e $E$. hystolitica em taxas de $3,9 \%, 12,7 \%$ e $8,8 \%$, respectivamente, a partir do exame de 639 espécimes fecais oriundos de índios Pacaánova, habitantes dos vales dos rios Guaporé e Mamoré, em Rondônia.

Situação potencialmente mais grave que as anteriormente descritas foi registrada por Confalonieri et al. (1989) entre os índios Yanomámi, na Serra dos Surucucus, estado de Roraima. Entre outros achados, registre-se a ocorrência de E. hystolitica em 12 (40\%), das 30 amostras de fezes analisadas.

Digno de nota, ainda, é o registro de caso grave de disenteria associado a Balantidium coli, descrito por Rees \& Shelley (1977), envolvendo uma mulher da tribo Yanomámi. Aliás, cabe assinalar que esse parasita também foi detectado, em associação com rotavírus, por ocasião da extensa epidemia (antes descrita) entre os indios Tiriyó.

Conquanto haja evidências de ampla dispersão dos enteroparasitas entre os silvícolas que habitam a Amazônia, não há relatos de ocorréncias epidêmicas relacionadas a tais enteropatógenos.

\section{Breves Comentários Finais}

1. As condições sanitárias insatisfatórias, a par de hábitos inadequados de higiene, configuram um panorama que prevalece amplamente entre os indígenas da Amazônia. Daí resulta a situação propícia à propagação de enteropatógenos bacterianos, viróticos e/ou parasitários, cujo mecanismo básico de transmissão envolve a via fecal-oral.

2. Os contatos cada vez mais freqüentes com o homem (ou ambiente) urbano, assim como o sedentarismo imposto aos silvícolas por restrições no que tange à ocupação da terra, ampliam o universo de fatores que os tornam mais vulneráveis aos microorganismos potencialmente enteropatogênicos.

3. No seu próprio hábitat, os silvícolas podem, eventualmente, estabelecer contato com animais que atuam como reservatórios de patógenos dotados de expressiva patogenicidade. Nesse particular, ressalte-se a elevada prevalência de anticorpos para rotavírus registrada em várias tribos amazônicas, assim como o isolamento desses agentes viróticos a partir de espécimes fecais oriundos de marsupiais. Um achado marcante, decorrente dos estudos de soroprevalência relacionados aos rotavírus, foi o de que, mesmo em comunidades com um contingente populacional reduzido, tais virus se estabelecem em caráter endêmico.

4. Tendo em vista as características do surto de diarréia por rotavírus que acometeu os Tiriyó, infere-se que, da eventual inexistência de imunidade para um determinado enteropatógeno, podem advir situações de particular gravidade e extensão. É plausível, pois, admitir-se a aplicação de vacina contra rotavírus (logo que disponível) em populações indígenas não-imunes. Presentemente, em Belém, Pará, está em curso estudo de campo com um imunizante específico, tetravalente (Linhares et al., 1991).

5. Ainda no tocante ao descrito no item anterior, impõe-se uma estrita vigilância quanto à possível introdução da cólera nas comunidades indígenas amazônicas, mormente quando se configura nitidamente a expansão da doença na região. Com efeito, há todo um elenco de fatores que propiciaria a sua 
propagação explosiva no seio dessas comunidades.

6. Entendemos como imperativo um esforço conjunto, envolvendo as diversas instituiçōes que interagem com as populações indígenas, no sentido de - a par dos procedimentos assistenciais vigentes - encetar-se um programa educativo que culmine com a minimização dos riscos quanto à introdução da cólera e outros processos mórbidos gastrintestinais que comprometam a saúde do nosso índio.

\section{AGRADECIMENTOS}

O autor agradece ao Dr. Habib Fraiha Neto e a Dra. Zéa Lins Laison por suas sugestões na elaboração do manuscrito.

\section{RESUMO}

\section{LINHARES, A. C. Epidemiologia das}

\section{Infecçōes Diarréicas entre}

Populações Indígenas da Amazônia. Cad. Saúde Públ., Rio de Janeiro, 8 (2): 121-128, abr/jun, 1992.

Enteropatógenos bacterianos, viróticos e parasitários têm sido associados freqüentemente a processos gastrintestinais entre indígenas da Amazônia. Entre os indios Parakanā, registrou-se freqüência da ordem de 4\% para Shigella flexneri. Por outro lado, taxas de soroprevalência de $98 \%$ para a toxina lábil de $E$. coli foram assinaladas no seio dos Menkrangnoti, Parakanā, Xikrín e Asuriní. Revelaram-se expressivos reservatórios de Salmonella sp. os edentados $(63 \%$ de positividade) e os marsupiais (20\%). Cepas de Shigella disenteriae foram detectadas em $4,2 \%$ de 40 índios Suruí avaliados, enquanto entre os Karitiána, isolaram-se, a partir de 85 coproculturas, uma amostra de Shigella boydii e 11 de $E$. coli. Os rotavírus se constituíram no agente causal do episódio epidêmico explosivo que acometeu os Tiriyó, em julho-agosto de 1977. Utilizando-se a contra-imuno-eletro-osmoforese, detectaram-se $25,6 \%$ de soroconversões, com base no exame de 127 amostras pareadas. $O$ sorotipo I de
Birmingham caracterizou-se como o agente causal da epidemia que abrangeu, pelo menos, $80 \%$ da população sob risco: crianças e velhos foram os mais atingidos. Estudos soroepidemiológicos empreendidos em 13 comunidades indígenas da região amazônica denotaram elevadas taxas de soropositividade (maiores de 50\%) para rotavírus, em termos gerais, conquanto os Parakanã Novo se tenham revelado não-imunes a esses agentes. $O$ gradativo aumento na freqüência de anticorpos com a idade sugere persistência dos rotavírus nessas comunidades. Ainda, o registro de resultados positivos em crianças de baixa idade sugere o caráter endêmico das infeç̧ōes. Expressivas taxas de positividade quanto à presença de anticorpos para rotavirus foram detectadas entre os Surui $(67,8 \%)$ e os Karitiána (77,4\%). Enteroparasitas de importância médica também foram detectados. $S$. stercoralis, Giardia Lamblia e Entamoeba hystolitica foram assinaladas, entre os Surui, em frequiências de $33,3 \%, 3,3, \%$ e $0,8 \%$, respectivamente. Esses mesmos patógenos foram detectados em frequiências, por ordem, de $3,9 \%, 12,7 \%$ e $8,8 \%$ ao exame de amostras fecais oriundas dos Pacaánova. Elevada taxa de Entamoeba hystolitica, cerca de $40 \%$, foi observada entre os Yanomámi. As precárias condições de saneamento em que vivem essas populações, os hábitos inadequados de higiene e possivel existência de reservatórios silvestres de enteropatógenos são alguns dos fatores que concorrem para o panorama descrito. Especial atenção merece ser dirigida, presentemente, às chances de propagação da cólera entre os silvícolas amazônicos.

Palavras-Chave: Ameríndios; Diarréias; Região Amazônica

\section{REFERÊNCIAS BIBLIOGRÁFICAS}

ALBERT, M. J.; BISHOP, R. F. \& SHANM, F. A., 1983. Epidemiology of rotavirus diarrhoea in the highlands of Papua, New Guinea, in 1979, as revealed by electrophoresis of genome RNA. Journal of Clinical Microbiology, 17: 162-164.

COIMBRA Jr., C. E. A. \& MELLO, D. A., 1981. Enteroparasitas e Capillaria sp. entre o grupo Surui, Parque Indígena Aripuanã, Rondônia. Memórias do Instituto Oswaldo Cruz, 76: 299. 302. 
COIMBRA Jr., C. E. A.; SANTOS, R. V.; TANUS, R. \& INHAM, T. M., 1985. Estudos epidemiológicos entre grupos indígenas de Rondônia. II Bactérias enteropatogênicas e gastrenterites entre os Suruí e Karitiána. Revista Fundaçāo da SESP, 30: $111-120$.

CONFALONIERI, U. E.; ARAÚJO, A. J. \& FERREIRA, L. F., 1989. Enteroparasitos em índios Yanomámi. Memórias do Instituto Oswaldo Cruz, 84: 111-113.

LINHARES, A. C.; GABBAY, Y. B.; FREITAS, R. B; MASCARENHAS, J. D. P.; OLIVEIRA, C. S.; BELLESI, N.; LAINSON, Z. C.; RAMOS, F. L. P. \& VALENTE, S. A., 1991. Estudo da imunogenicidade, eficácia e inocuidade de uma vacina tetravalente contra rotavírus em Belém, Pará, Brasil: breves consideraçōes sobre os primeiros doze meses. Imunizaçōes - Atualização, 4: 1-3.

LINHARES, A. C.; PEREIRA, J. D. M.; GABBAY, Y. B. \& NAKAUTH, C. M., 1986a. Rotavirus infection in wild marsupials (Didelphis marsupialis) of the Amazon region. Transactions of the Royal Society of Tropical Medicine and Hygiene, 80: 20-24.

LINHARES, A. C.; SALBE, E. V.; GABBAY, Y. B. \& REES, N., 1986b. Prevalence of rotavirus antibody among isolated South American Indian communities. American Journal of Epidemiology, 123: 699-709.

LINHARES, A. C.; PINHEIRO, F. P.; FREITAS, R. B.; GABBAY, Y. B.; SHIRLEY, J. A. \& BEARDS, G. M., 1981. An outbreak of rotavirus diarrhea among a nonimmume isolated South American Indian community. American Journal of Epidemiology, 113: 703-710.

LINS, Z. C., 1983. Enteroinfeç̧ões Bacterianas. In: Saúde na Amazônia ( A. C. Linhares, coord.), 2: ed., pp. 97-98, São Paulo: ANPES.

PINHEIRO, F. P.; BENSABATH, G.; ANDRADE, A. H. P.; LINS, Z. C.; FRAIHA, H.; TANG, A. T.; LAINSON, R.; SHAW, J. J. \& AZEVEDO, M., 1974. Vigilancia $\mathrm{y}$ investigación de las enfermedades infecciosas a lo largo de la carretera Transamazonica del Brasil. Boletin de la Oficina Sanitaria Panamericana, 77: 187-198.

REES, R. G. P. \& SHELLEY, A. J., 1977. Estimativa da resposta a clortetraciclina em um caso grave de disenteria por Balantidium coli. Acta Amazónica, 7: 47-49.

SANTOS, R. V.; LINHARES, A. C. \& COIMBRA Jr., C. E. A., 1991. Estudos epidemiológicos entre grupos indígenas de Rondônia. IV. Inquérito sorológico para rotavirus entre os Suruí e Karitiána. Revista de Saúde Pública, 25: 230 232.
SANTOS, R. V.; COIMBRA Jr., C. E. A. \& OTT, A. M. T., 1985. Estudos epidemiológicos entre grupos indígenas de Rondônia. III. Parasitoses intestinais nas populações dos vales dos rios Guaporé e Mamoré. Cadernos de Saúde Pública, 1: 467-477. 